\title{
Assessment of Exposure to Voices and Noise via Earphones in Manufacturing Industry Workers in Japan
}

\author{
Tomo NAKAO $^{1}$, Masazumi KAKei ${ }^{1}$, Ikuno ArAKI ${ }^{2}$, Takao Tsutsui ${ }^{1}$, Noriaki SATOH ${ }^{3}$, \\ Jinro INOUE ${ }^{1}$ and Seichi HORIE ${ }^{1}$ \\ ${ }^{1}$ Department of Health Policy and Management, Institute of Industrial Ecological Sciences, University of Occupational \\ and Environmental Health, Japan, ${ }^{2}$ Medicine \& Occupational Health, EMG Marketing Godo Kaisha, ${ }^{3}$ Shared-Use \\ Research Center, Facility for Education and Research Support, University of Occupational and Environmental \\ Health, Japan
}

\begin{abstract}
Assessment of Exposure to Voices and Noise via Earphones in Manufacturing Industry Workers in Japan: Tomo NAKAO, et al. Department of Health Policy and Management, Institute of Industrial Ecological Sciences, University of Occupational and Environmental Health, Japan-Objectives: There is concern that sound via earphones and headphones attached to headsets used in workplaces may be a risk factor for noise-induced hearing loss (NIHL). Although there are some previous studies investigating exposure to noise from headphones, almost none have assessed the risks to workers who use earphones. We assessed exposure to noise among workers who regularly wear earphones in noisy workplaces. Methods: The subjects of this study were 21 workers who regularly wear earphones in three manufacturing companies in Japan. The sound pressure output from earphones and personal exposure to occupational noise was measured for each worker. A noise-dosimeter was used to measure individual exposure to occupational noise. The sound pressure output from the earphones was measured by recording the electric signal with a data recorder attached to the earphones, and the recording was analyzed by playing it back in the laboratory through a sound analyzer via an ear simulator. Results: The mean scores for personal exposure and earphone output $L_{\text {Aeq }}$ were $87.9 \mathrm{~dB}$ and $87.6 \mathrm{~dB}$, respectively. Earphone output $L_{\text {Aeq }}$ exceeded $85 \mathrm{~dB}$ for two-thirds of the subjects. Nearly all the subjects lacked hearing protection devices (HPDs) on their earphones. Conclusions: The results suggest that workers who use earphones in noisy workplaces are exposed to the
\end{abstract}

Received Dec 15, 2013; Accepted Apr 22, 2014

Published online in J-STAGE Jun 21, 2014

Correspondence to: T. Nakao, Department of Health Policy and Management, Institute of Industrial Ecological Sciences, University of Occupational and Environmental Health, 1-1 Iseigaoka, Yahatanishi-ku, Kitakyushu, Fukuoka 807-8555, Japan (e-mail: tomonakaouoeh@gmail.com) following NIHL risk factors: (1) they are deprived of the opportunity to fit appropriate HPDs, and (2) the sound pressure output from the earphones themselves exceeds the occupational exposure limit.

(J Occup Health 2014; 56: 285-291)

Key words: Ear protective devices, Hearing loss, Telecommunications

Occupational noise countermeasures are being progressed in Japan in accordance with the Industrial Safety and Health Law and the Guidelines for the Prevention of Noise-Induced Impairments. The results of medical examinations intended for the health management of workers in noisy workplaces found 37,262 positive findings, representing a positive finding rate of $16.9 \%$, and both the number and rate were the highest found for specified items in the main medical examinations ${ }^{1)}$. In the United States, hearing loss is one of the 21 priority areas in the National Occupational Research Agenda. Furthermore, in recent years, there has been increased interest in auditory disorders caused by listening to music at a high volume through earphones or headphones, which has become more widespread with the growing use of portable audio devices ${ }^{2-4)}$. Consequently, noiseinduced hearing loss (NIHL) is becoming a widespread problem.

Telecommunications devices are becoming more widely used in workplaces recently because of the growing use of mobile telephone devices and the advances in automation, rationalization and streamlining. The telephone devices used by workers for communications normally have a headset with a receiver and microphone attached. Call center employees, for example, make large numbers of calls to customers using headsets. Headsets are used in manufacturing companies by workers to report the 
status of instruments and gauges to control rooms as they move about and by crane operators and slingers to communicate with each other while operating heavy machinery. Previous international studies of telecommunications and broadcasting industry operators, airport employees, and US Department of Defense employees reported that voices and noise heard through headsets may cause hearing loss. In each case, the headsets were headphones worn over the ears (supra-aural headphones) ${ }^{5-9)}$. Although inserttype and intra-concha-type earphones are widely used in manufacturing companies in Japan, very few studies of earphones have been reported ${ }^{10)}$. Our investigations found no studies of workers wearing earphones in the manufacturing industry.

The aim of the present study was to assess hearingloss hazards by measuring the voice and noise levels of earphones among workers who wear earphones in the foundry, steel and oil refinery industries.

\section{Materials and Methods}

Fields and subjects

This study was conducted in three companiesA, B and C-in November 2007, January 2008 and October 2007, respectively.

Company A, a foundry, was engaged in the manufacture of rolling mill rolls used in the steel industry. Crane operators and workers on the ground communicated with each other via a radio telecommunication device, which enabled two-way communication, with the speaker communicating through a microphone positioned near the mouth without needing to press a button to speak.

Measurements were also taken at Company B, a steelworks factory that uses a cold rolling process. Workers communicated through radio telecommunication devices to report the production line status, when changing rolling mill rolls, or to give instructions regarding repair work. The radio devices allowed for one-way communication, with the speaker holding down the microphone button while speaking; the speaker could be heard by all workers carrying a radio.

One-way radios were used at Company $\mathrm{C}$, an oil refinery. Headsets were used by workers who regularly patrol the refinery to report the status of plant gauges and instruments throughout the refinery, and almost all workers wore a headset at all times.

Companies A and C used PR-17 (Hitachi Kokusai Electric Inc., Tokyo, Japan) insert-type earphones, while Company B used EMC-3 (JVC Kenwood Corporation, Yokohama, Japan) intra-concha-type earphones. All the workers in this study wore an earphone in one ear and an earplug in the other ear for 8 hours per day in the workplace. When work- ing in an office, they took out the earplug only. The workers therefore spent almost all their work time wearing an earphone. Other than offices, all of the work zones in this study were designated as noisy workplaces in which it was obligatory for workers to wear a hearing protection device (HPD).

The subjects selected for this study used an earphone and could hear at a $30 \mathrm{~dB}$ hearing level (HL) with the ear in which the earphone was normally used, as determined by pure-tone audiometry at $4 \mathrm{kHz}$ in a regular health check. We excluded three subjects from our study in company B because they did not meet these criteria. A total of 21 workers were selected from the three companies. The subjects were all males aged between 21 and 51 years $(32.0 \pm 8.8$ years $)$. They had been in their current jobs for periods between 8 and 240 months (96.7 \pm 58.2 months) (Table 1$)$. This study was conducted after obtaining the approval of the Ethics Committee of the University of Occupational and Environmental Health, Japan, and the written informed consent of the subjects.

Measurement of personal noise exposure in the workplace

A noise dosimeter (Logging Noise Dose Meter Type 4443; Brüel \& Kjær, Nærum, Denmark) was used to measure personal exposure in the workplace environment. The measurement range was $70-140 \mathrm{~dB}$. A noise dosimeter microphone was worn by workers at the collar, and a data recorder was carried in a pouch worn at the waist. The measurement period was half a day (approximately 4 hours), the dynamic response was set to FAST (time constant, $125 \mathrm{~ms}$ ), and the equivalent continuous A-weighted sound pressure level was measured every 10 seconds $\left(L_{\text {Aeq, 10sec }}\right)$.

\section{Recording the earphones input signal}

The subjects were exposed to the same level of noise at the same workplace for 8 hours each day. We asked them to wear the dosimeter and data recorder (EZ7510; NF Corporation, Yokohama, Japan) for at least 3 hours during their work. The voices and noise output from the earphones were electronically recorded by splitting the earphone cable connected to the transceiver, connecting one of the cables to a data-recorder and the other to the transceiver. The data recorder was carried by the subjects in a pouch with the noise dosimeter, and the data were recorded continuously. The measurement period was half a day (approximately 4 hours), the same as for personal exposure measurement.

$L_{\text {Aeq }}$ measurement in laboratory

The data recorded by the noise dosimeters and 
Table 1. Comparison of age, employment term, estimated talking time and $L_{\text {Aeq }}$

\begin{tabular}{|c|c|c|c|c|c|c|c|c|c|c|c|c|c|}
\hline & & \multicolumn{3}{|c|}{ Company A } & \multicolumn{3}{|c|}{ Company B } & \multicolumn{3}{|c|}{ Company $\mathrm{C}$} & \multicolumn{3}{|c|}{ Total } \\
\hline & & $\mathrm{n}$ & Mean & SD & $\mathrm{n}$ & Mean & SD & $\mathrm{n}$ & Mean & SD & $\mathrm{n}$ & Mean & SD \\
\hline \multicolumn{14}{|l|}{ Subjects' basal data } \\
\hline Age & [yr] & 3 & 42.3 & 6.1 & 8 & 31.5 & 8.1 & 10 & 29.2 & 8.5 & 21 & 32.0 & 8.9 \\
\hline Term & [mo] & 3 & 142.0 & 60.7 & 8 & 99.0 & 69.3 & 10 & 81.2 & 46.9 & 21 & 96.7 & 58.2 \\
\hline \multicolumn{14}{|l|}{ Result } \\
\hline Estimated talking time & [sec] & 3 & 263.3 & 159.5 & 8 & 417.5 & 182.8 & 10 & 385.0 & 211.6 & 21 & 380.0 & 192.3 \\
\hline$L_{\text {Aeq,2h }}(\mathrm{ep})$ & {$[\mathrm{dB}]$} & 3 & 89.0 & 3.0 & 8 & 84.1 & 8.7 & 10 & 89.9 & 9.6 & 21 & 87.6 & 8.8 \\
\hline$L_{\text {Aeq, }, 2 \mathrm{~h}}(\mathrm{dm})$ & {$[\mathrm{dB}]$} & 3 & 92.4 & 1.4 & 8 & 90.2 & 6.6 & 10 & 84.7 & 4.3 & 21 & 87.9 & 5.8 \\
\hline
\end{tabular}

the data recorders were brought back to the laboratory (Shared-Use Research Center at the University of Occupational and Environmental Health, Japan), and the $L_{\text {Aeq }}$ was measured. Although the various data were recorded for each subject for 4 hours, the data for the first 30 minutes and from the 2.5 hour mark were deleted. This left 2 hours of data, which was used as the $L_{\text {Aeq,2h }}$. In the case of some of the subjects, the data from this recording period were deleted because of a shift changeover and the time taken for subjects to move between their work zones and the place where the devices were fitted, as well as time taken for the noise dosimeters and data recorders to be fitted and removed.

The equivalent continuous sound pressure levels of the workplace environments recorded and assessed by the noise dosimeter and data recorder were defined as $L_{\text {Aeq, } 2 \mathrm{~h}}(\mathrm{dm})$ and $L_{\text {Aeq,2h }}(\mathrm{ep})$, respectively.

\section{Downloading data recorded by the dosimeter}

Proprietary noise dosimeter software (VP7790; Brüel \& Kjær) was used to download the data recorded on the dosimeter, and the $L_{\text {Aeq,2h }}(\mathrm{dm})$ data were extracted for each subject. Because the measurement range of the dosimeter was $70-140 \mathrm{~dB}$, we substituted $70 \mathrm{~dB}$ for the undetectable sound level to calculate $L_{\text {Aeq,2h }}(\mathrm{dm})$.

$L_{\text {Aeq }}$ measurement of voices and noise played through earphones

The voices and noise electronically recorded with the data recorder were replayed through an earphone and measured for $L_{\text {Aeq }}$ every 10 seconds using a frequency analyzer (Type 7700; Brüel \& Kjær) via an ear simulator (Type $4157+$ DB2012; Brüel \& Kjær). $L_{\text {Aeq, } 2 \mathrm{~h}}$ (ep) was calculated from the $L_{\text {Aeq,10sec }}$ (ep). The earphone and ear simulator were placed in an anechoic test chamber (Type 4222; Brüel \& Kjær) to insulate them from any other noise in the laboratory. This method enabled us to measure the earphone signals free of environmental noise.

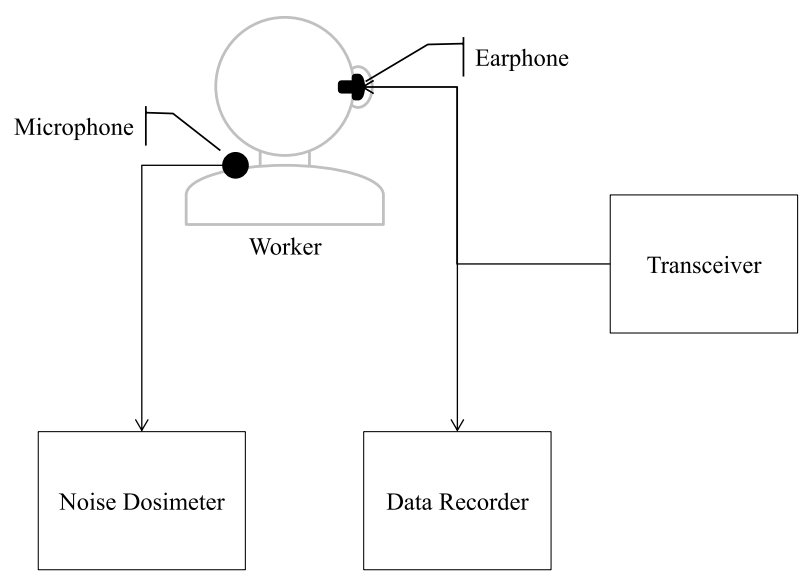

Fig. 1. Block diagram of the data recording system used in the fields. The noise dosimeter and data recorder were worn continuously by the workers in a pouch at the waist for the entire work period.

\section{Statistical methods}

We performed the Shapiro-Wilk test to evaluate normality and Pearson's correlation analysis between $L_{\text {Aeq,2h }}(\mathrm{dm})$ and $L_{\text {Aeq,2h }}(\mathrm{ep})$. The statistical analysis was conducted using the SAS statistical software (v. 9.3 for Windows; SAS Institute, Cary, NC, USA).

\section{Results}

The estimated talking time was defined as the amount of time during which the sound pressure was detected at $85 \%$ or more of the maximum output from each subject's earphone and was calculated to be $380 \pm 192.3$ out of 7,200 seconds analyzed (Table 1). The mean scores for $L_{\text {Aeq,2h }}(\mathrm{dm})$ and $L_{\text {Aeq, } 2 \mathrm{~h}}(\mathrm{ep})$ of all subjects were $87.9 \mathrm{~dB}$ and $87.6 \mathrm{~dB}$, respectively.

Typical changes over time in individual exposure to occupational noise and output from earphones are shown in Fig. 3. The results of our study showed the following two patterns. The results for Company A show that the sound output from earphones was usually approximately $75 \mathrm{~dB}$ and exceeded $90 \mathrm{~dB}$ during conversation (top graph in Fig. 3). The 


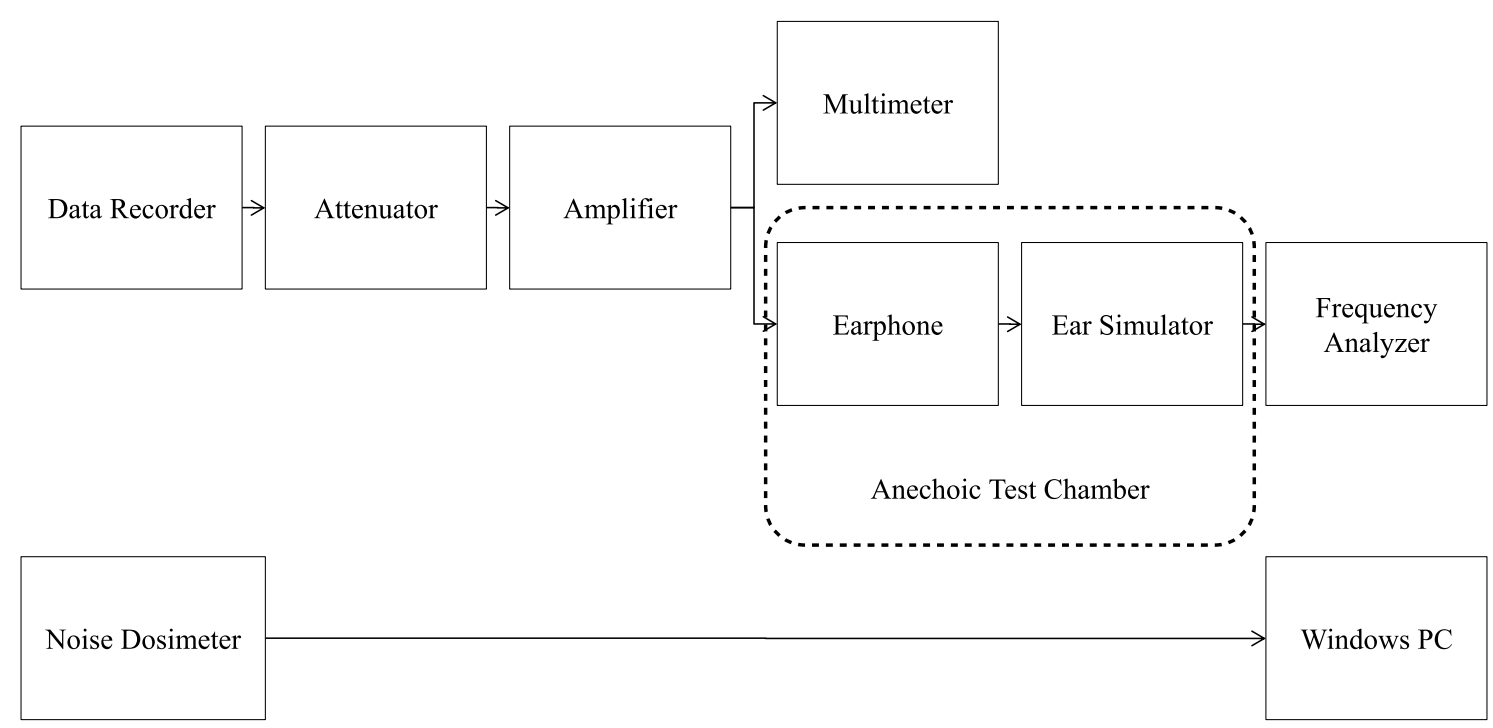

Fig. 2. Block diagram of the $L_{\text {Aeq }}$ measurement system in the laboratory.

results for Company $\mathrm{B}$ show that the sound pressure from earphones was higher than the occupational noise during conversation but that it was approximately $55 \mathrm{~dB}$ at other times (middle graph in Fig. 3). Companies $\mathrm{C}$ and $\mathrm{B}$ demonstrated the same pattern. Company $\mathrm{C}$ had an office area that was not a noisy work zone, so the dosimeter noise measurements were lower after 1 hour and 20 minutes. However, the output from earphones remained high. One-third octave analysis of the output from earphones is shown in Fig. 4. It was established that the output from earphones was mainly between 400 and 2,666 Hz.

The distributions of $L_{\text {Aeq,2h }}(\mathrm{dm})$ and $L_{\text {Aeq,2h }}$ (ep) are shown in Fig. 5. The proportions of workers who experienced sound pressures in excess of $85 \mathrm{~dB}$ were $71.4 \%(15 / 21)$ and $66.7 \%(14 / 21)$ for $L_{\text {Aeq,2h }}(\mathrm{dm})$ and $L_{\text {Aeq, } 2 \mathrm{~h}}$ (ep), respectively.

$L_{\text {Aeq, } 2 \mathrm{~h}}(\mathrm{dm})$ and $L_{\mathrm{Aeq}, 2 \mathrm{~h}}(\mathrm{ep})$ are normally distributed, as $p=0.50$ and $p=0.99$, respectively (Shapiro-Wilk test). Analysis of the correlation between $L_{\text {Aeq, } 2 \mathrm{~h}}(\mathrm{ep})$ and $L_{\text {Aeq.2h }}(\mathrm{dm})$ showed a Pearson's correlation coefficient (Pearson's $r)$ of $0.34(p=0.13)$.

\section{Discussion}

This study assessed the level of personal exposure to noise among workers who wore earphones in noisy workplaces. We found a small number of previous studies that assessed output from headphones ${ }^{5-9)}$, but there were very few studies on earphones. Idota et al. (2010) reported an analysis of sound from earphones, which actually had a sample of only one worker ${ }^{10)}$. We believe one of the merits of the present study is that it individually analyzed the output from the earphones of 21 workers and assessed their personal exposure to noise.

The changes in sound pressure level from the earphones revealed two patterns (Fig. 3). One pattern shows a difference of nearly $30 \mathrm{~dB}$ between the sound pressure level during conversation and the level at other times, while the other pattern shows a difference that is not so large. The devices used at Companies $\mathrm{B}$ and $\mathrm{C}$ require the speaker to press a button on the microphone when transmitting, which means that nothing is transmitted when the button is not being held down. However, the devices at Company A transmit at all times, which means noise, factory warning sounds and impact noises can be heard through the earphones, even when workers are not conversing. The changes in earphone output appear to be attributable to this difference in telecommunication devices. In environments where continuously transmitting telecommunication devices are used, if workers work close to sources of noise, workplace noise as well as voices will be transmitted through the devices, raising the level of exposure to noise via earphones.

Although the subjects were exposed to the same level of noise at the same workplace for 8 hours each day, we only used 2 hours of recorded data for our analysis. We considered that these 2 hours well represent the average exposure of the workers during work per day. The mean personal noise exposure $\left(L_{\text {Aeq,2h }}\right.$ $(\mathrm{dm})$ ) measured at the three types of workplaces in this study was $87.9 \mathrm{~dB}$. This exceeds the occupational exposure limit (OEL), which is $85 \mathrm{~dB}^{11)}$. According to the law and guidelines in Japan, if such workplaces do not take adequate measures to control noise sources and to reduce noise, they may be directed to use HPDs $^{12,13)}$. We used $70 \mathrm{~dB}$ as a substitute for levels 

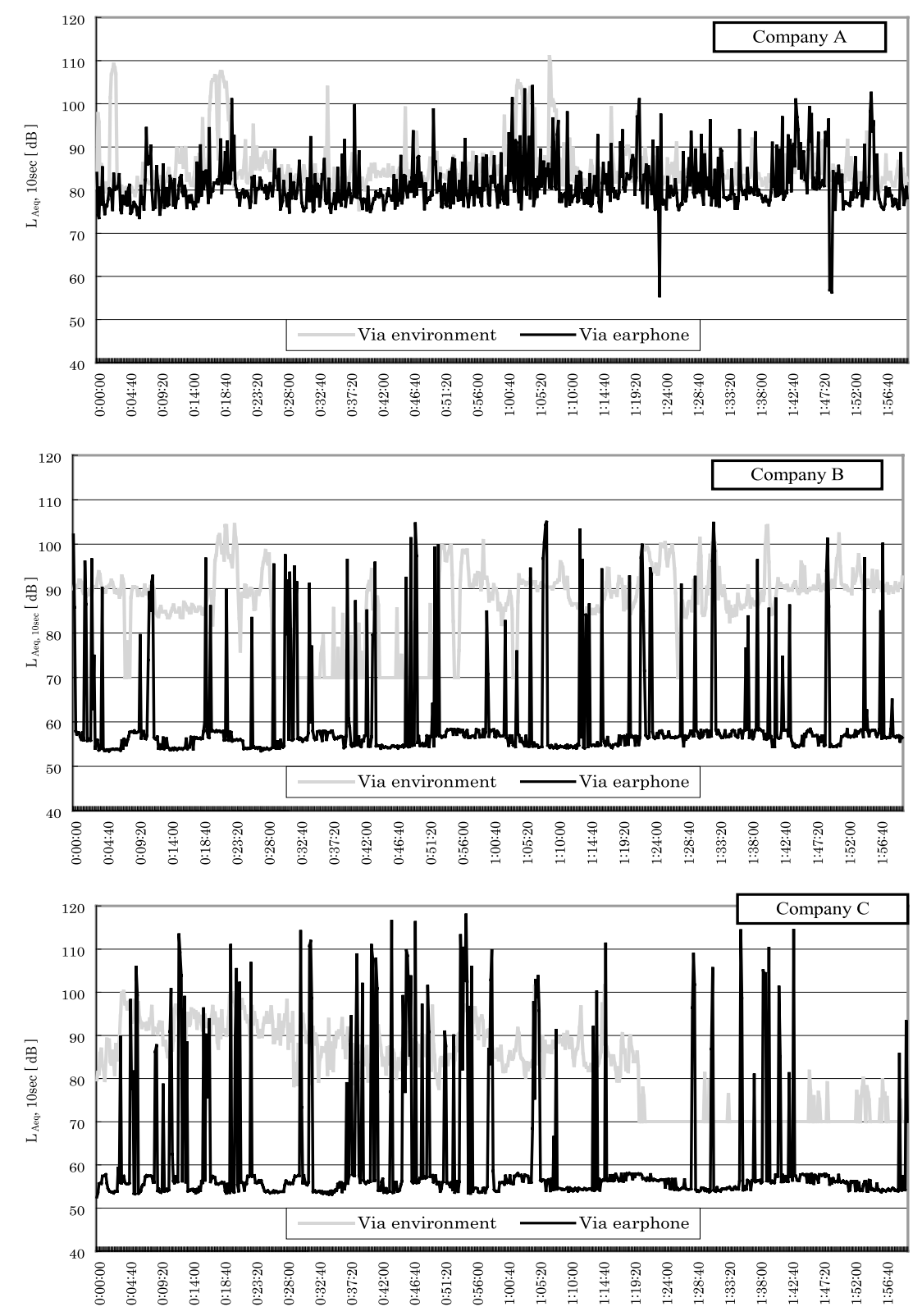

Fig. 3. Example of the fluctuation of the noise from the workplace and from earphones. Sound from earphones was usually approximately $75 \mathrm{~dB}$ at Company A because they used two-way communications devices. Company B and Company $\mathrm{C}$ used one-way devices that require the speaker to press a button before speaking, so the output from the earphones when not talking was low. The baseline of the line chart represents the residual noise transmitted through telecommunication devices and is not the environmental noise level attenuated by the earphones.

of less than $70 \mathrm{~dB}$; therefore, the level might have been overestimated compared with the actual noise exposure. However, $70 \mathrm{~dB}$ was negligible compared with $85 \mathrm{~dB}$ in terms of the sound power calculation. Nearly all the 21 subjects wore an earphone in one ear and an earplug in the other ear. The earphones commonly used inside factories for communica- tion do not have an adequate sound attenuation level compared with that required for HPDs. Accordingly, workers who use telecommunication devices in noisy workplaces are at risk of NIHL because they cannot use an appropriate HPD.

The mean score for $L_{\text {Aeq.2h }}$ (ep) was $87.6 \mathrm{~dB}$, and two thirds of the workers exceeded $85 \mathrm{~dB}$. This 


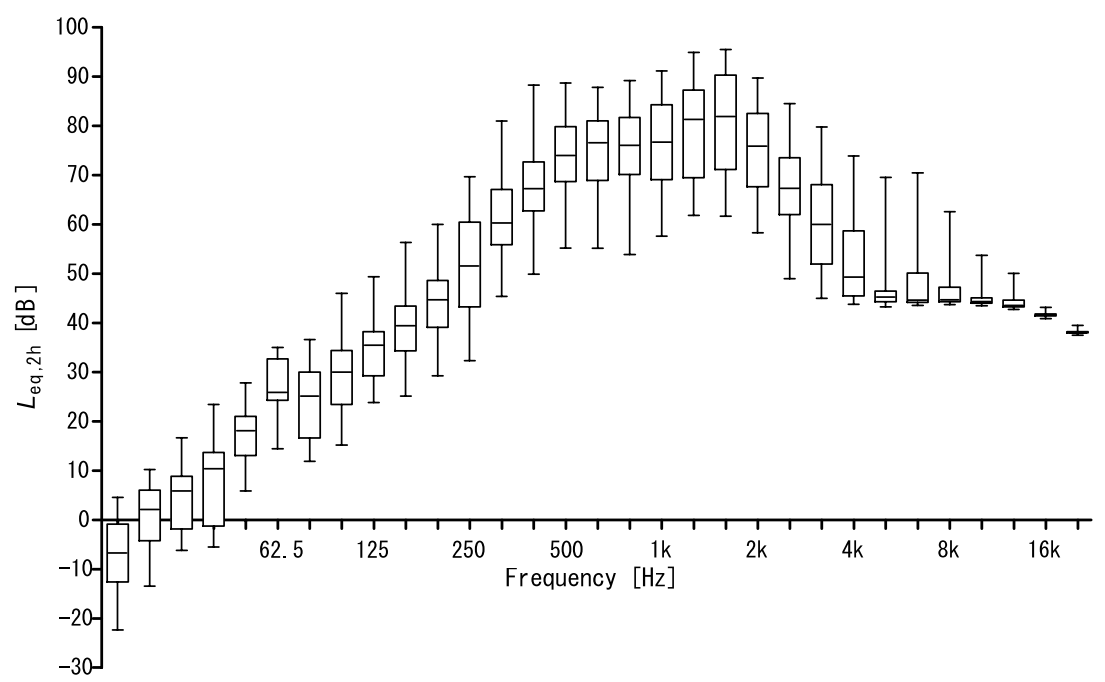

Fig. 4. Frequency characteristics of voices and noise reproduced by earphones.

suggests that without an possible protection, the sound pressure level of voice transmissions from radios exceeds the OEL. The proportion of time that workers talked was approximately $5 \%$, a small proportion of the analyzed time; however, it did include loud noise in excess of $100 \mathrm{~dB}$. Considering that the permissible daily exposure time to noise in excess of $100 \mathrm{~dB}$ is 15 minutes $^{12)}$, it would appear that the sound pressure to which workers in this study were exposed through their earphones may put them at a sizable risk of NIHL. Additionally, there were three subjects we had to exclude from our study at company $\mathrm{B}$ because they exceeded our inclusion criteria of no more than $30 \mathrm{~dB} \mathrm{HL}$ at $4 \mathrm{kHz}$.

According to specialist texts, the smaller the signalto-noise ratio (SNR), the lower the speech intelligibility ${ }^{14)}$, while Dajani et al. (1996) confirmed a positive correlation between environmental noise and headset volume ${ }^{8)}$. That is, when spoken communication occurs in noisy circumstances, the risk of NIHL increases, as the transmission volume needs to be increased to improve (increase) the SNR in response to such situations when comprehension becomes difficult because of masking. However, the correlation analysis in this study could not find a statistically significant correlation between $L_{\text {Aeq,2h }}(\mathrm{dm})$ and $L_{\text {Aeq,2h }}(\mathrm{ep})$ (Pearson's $\mathrm{r}=0.34, p=0.13)$, and the results did not match up with the finding of the study above. Previous studies investigated non-noisy workplaces, such as call centers and aircraft control rooms, as well as noisy workplaces at airports and found that the range of occupational noise levels to which subjects were exposed was large, at between 64 and $96 \mathrm{dBA}$ (and therefore the range of outputs from headsets was also large ${ }^{6}$. In contrast, our study examined noisy workplaces only

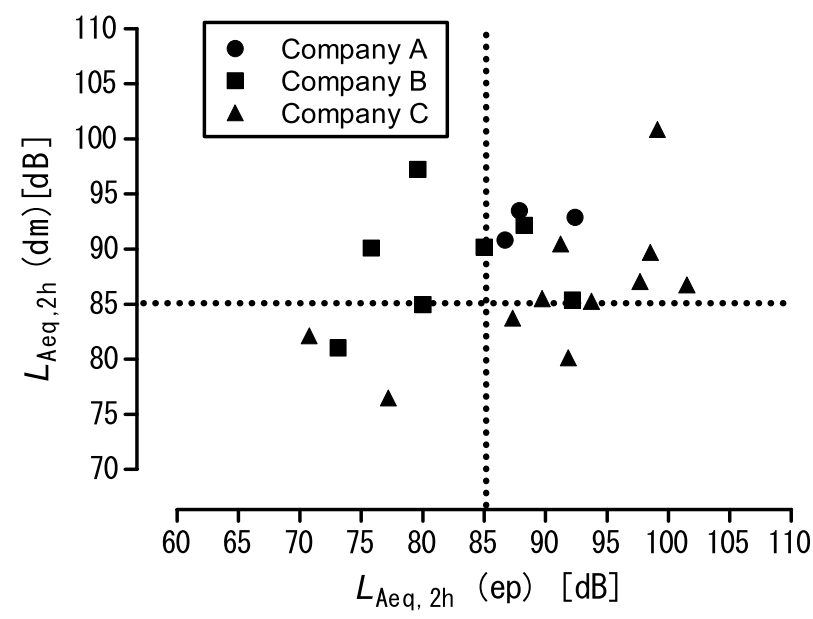

Fig. 5. Correlation between $L_{\text {Aeq,2h }}(\mathrm{ep})$ and $L_{\text {Aeq, } 2 \mathrm{~h}}(\mathrm{dm}) . L_{\text {Aeq, } 2 \mathrm{~h}}$ (ep) is the $L_{\text {Aeq }}$ obtained from analysis of 2 hours of earphone output. $L_{\text {Aeq, } 2 \mathrm{~h}}(\mathrm{dm})$ is the $L_{\text {Aeq }}$ value for 2 hours of personal noise exposure measured with a noise-dosimeter.

and found an $L_{\text {Aeq,2h }}(\mathrm{dm})$ range of 76.5 to $100.8 \mathrm{~dB}$, which is smaller than the range in previous studies (and therefore the $L_{\text {Aeq,2h }}$ (ep) range was also small). Consequently, when considering workplace countermeasures, we should take account of the tendency that the output from earphones becomes louder in a noisy workplace, although this finding was not verified by this study.

This study therefore suggests that workers who work in noisy workplaces wearing headsets are at risk of not being able to use an appropriate HPD and are at risk of sound from their earphones occurring at levels that may cause auditory disorder. Thus, it 
would appear there is a need to strengthen measures to prevent hearing difficulty so as not to foreshorten careers, particularly in occupations that require speech recognition. Specific measures that could be investigated include the selection of insulating earphones ${ }^{15}$, recommendation of earmuffs together with earphones, determination of the maximum earphone output and instruction of workers to ensure they do not set the earphone volume louder than necessary.

Exposure from earphones and headsets can be measured for assessment by either inserting a microphone into the actual ear ${ }^{6,16)}$ or using simulated environments, such as artificial ears or ear simulators ${ }^{5,7,9)}$. Hirahara et al. (2010) reported variation between the measurements using real ears and measurements in the laboratory, particularly for insert-type earphones ${ }^{5)}$. Possible reasons for this variation include inadequate outer ear masking for earphones and subsequent leakage in the real ear environment and measurement in the low-frequency range below $600 \mathrm{~Hz}$ in the laboratory, consequently rendering relatively high assessments. The present study assessed sound pressure exposure from earphones using an ear simulator among workers using intra-concha-type earphones (Company B) and insert-type earphones (Companies $\mathrm{A}$ and $\mathrm{C}$ ), including sound below $600 \mathrm{~Hz}$ in the main frequency range. It was found that the $L_{\text {Aeq,2h }}$ (ep) scores were higher for Companies $\mathrm{A}$ and $\mathrm{C}$ than Company $\mathrm{B}$; therefore the real-ear noise exposure levels for Companies $\mathrm{A}$ and $\mathrm{C}$ may have been lower than our measurements obtained using an ear simulator in the laboratory.

$L_{\text {Aeq }}(\mathrm{ep})$ and $L_{\text {Aeq }}(\mathrm{dm})$ were measured separately in this study. In the real-ear environment, workers were exposed to attenuated $L_{\text {Aeq }}(\mathrm{dm})$ in addition to the $L_{\text {Aeq }}$ (ep) exposure. The sound-insulation performance of the earphones measured in this study was not as high as that of the earplugs, and this indicates that the attenuated $L_{\text {Aeq }}(\mathrm{dm})$ must also be included when considering auditory disorder. While this study suggests there is a risk of auditory disorder from an earphone's output alone, we would also suggest there is a need to conduct assessments that include exposure to noise from the workplace environment.

\section{References}

1) Ministry of Health, Labour and Welfare: Results of specific medical examination. [Online]. 2007 [cited 2013 Oct 26]; Available from: URL: http://www. mhlw.go.jp/bunya/roudoukijun/anzeneisei11/02.html

2) Ahmed S, Fallah S, Garrido B, Gross A. Use of portable audio devices by university students. Can Acoust 2007; 35: 35-54.
3) Hirahara T, Aoyama Y, Otani M. Acoustic characteristics of earphones and issues of IEC60711 coupler. Journal of the Acoustical Society of Japan 2010; 66: 45-55 (in Japanese).

4) Zogby J, Bruce J, Wittman R. Survey of Teens and Adults about the Use of Personal Electronic Devices and Head Phones. [Online]. 2006 [cited 2013 Oct 26]; Available from: URL: www.asha.org/uploadedFiles/about/news/atitbtot/zogby_survey2006.pdf

5) Williams W, Presbury J. Observations of noise exposure through the use of headphones by radio announcers. Noise Health 2003; 5: 69-73.

6) Chiusano SV, Lees PSJ, Breysse PN. An occupational noise exposure assessment for headset-wearing communications workers. Appl Occup Environ Hyg 1995; 10: 476-81.

7) Dajani H, Kunov H. Real-time method for the measurement of noise exposure from communication headsets. Appl Acoust 1996; 49: 209-24.

8) Alexander RW, Koenig AH, Cohen HS, Lebo CP. The effects of noise on telephone operators. J Occup Med 1979; 21: 21-5.

9) Patel JA, Broughton K. Assessment of the noise exposure of call centre operators. Ann Occup Hyg 2002; 46: 653-61.

10) Idota $\mathrm{N}$, Horie $\mathrm{S}$, Tsutsui $\mathrm{T}$, Inoue J. Temporary threshold shifts at 1500 and $2000 \mathrm{~Hz}$ induced by loud voice signals communicated through earphones in the pinball industry. Ann Occup Hyg 2010; 54: 842-9.

11) Japan Society for Occupational Health: Recommendation of occupational exposure limits. J Occup Health 2012; 54: 387-404.

12) Japan International Center for Occupational Safety and Health: Guidelines for the Prevention of NoiseInduced Impairments. [Online]. 1992 [cited 2013 Oct 26]; Available from: URL: http://www.jniosh. go.jp/icpro/jicosh-old/english/guideline/Guide-1.html

13) Japan International Center for Occupational Safety and Health: Industrial Safety and Health Law. [Online]. 2006 [cited in 2013 Oct 26]; Available from: URL: http://www.jniosh.go.jp/icpro/jicosh-old/ japanese/country/japan/laws/01_occ/index.html

14) Berger EH. Speech Communications and Signal Detection in Noise. In: Berger E, Royster L, Royster J, et al., editors. The Noise Manual 5th ed. Virginia (USA): AIHA; 2003. p.587.

15) Nakao $T$, Horie $S$, Tsutsui $T$, Kawanami $S$, Inoue J. Earplug-type earphone with built-in microphone improves monosyllable intelligibility in noisy environments. J Occup Healh 2008; 50: 194-6.

16) Macrae JH. Hearing conservation standards for occupational noise exposure of workers from headphones or insert earphones. Aust J Audiol 1995; 17: 107-14. 